\title{
Assigning responsibility for country-level warming to individual major emitters
}

\section{Other Conference Item}

Author(s):

Beusch, Lea (D); Nauels, Alexander; Gudmundsson, Lukas (D); Schleussner, Carl-Friedrich; Seneviratne, Sonia I. (1)

Publication date:

2021

Permanent link:

https://doi.org/10.3929/ethz-b-000528415

Rights / license:

Creative Commons Attribution 4.0 International

Originally published in:

EGUsphere, https://doi.org/10.5194/egusphere-egu21-8614 


\title{
EGU21-8614
}

https://doi.org/10.5194/egusphere-egu21-8614

EGU General Assembly 2021

(c) Author(s) 2022. This work is distributed under

the Creative Commons Attribution 4.0 License.

\section{Assigning responsibility for country-level warming to individual major emitters}

\author{
Lea Beusch ${ }^{1}$, Alexander Nauels ${ }^{2,3}$, Lukas Gudmundsson ${ }^{1}$, Carl-Friedrich Schleussner ${ }^{2,4}$, and Sonia I. \\ Seneviratne ${ }^{1}$ \\ ${ }^{1}$ Institute for Atmospheric and Climate Science, ETH, Zurich, Switzerland (lea.beusch@env.ethz.ch) \\ ${ }^{2}$ Climate Analytics, Berlin, Germany \\ ${ }^{3}$ Australian-German Climate \& Energy College, University of Melbourne, Parkville, Australia \\ ${ }^{4}$ Integrative Research Institute on Transformations of Human-Environment Systems, Humboldt-Universität zu Berlin, \\ Berlin, Germany
}

Human influence on climate is not usually disentangled in the contribution of single emitters, especially when assessing changes and impacts in individual countries. However, such information could help individual countries understand their role in driving climate change and thus aid them in committing to fair and evidence-based emission reduction targets. Here, we quantify the contribution of single emitters to country-level median warming and extremes based on historical emissions and currently pledged policy targets. Thereby, we focus on the five largest historical emitters - China, the United States of America, the European Union, India, and Russia. While large ensembles are needed for this task, the computational burden of running full Earth System Models (ESMs) renders it impossible to answer our question with actual ESMs. Instead, we combine a physical global mean temperature emulator (Meinshausen et al., 2009) with a statistical spatially-resolved ESM emulator (Beusch et al., 2020) to create millions of temperature field time series. Our setup accounts for three major sources of uncertainty: (i) uncertainty in the global temperature response to greenhouse gas emissions, (ii) uncertainty in the regional response to global warming, (iii) uncertainty due to internal climate variability.

We find that historically rare hot years (occurring about once every 100 years in pre-industrial times) are expected at least every second year in $89 \%$ (likely range: $71-100 \%$ ) of all countries by 2030. Without the emissions of the top five emitters over the time period during which policy makers had been informed about the looming anthropogenic climate crisis, i.e., after the first IPCC report of 1990, it would be $40 \%(10-64 \%)$ of all countries instead. Furthermore, when considering all current and projected emissions until 2030, $8 \%$ (0 - $54 \%)$ of countries are headed towards surpassing $2.0^{\circ} \mathrm{C}$ of warming since pre-industrial times by 2030 . If all nations followed the same per capita emissions as the USA since the 2015 Paris Agreement, the percentage of countries surpassing $2.0^{\circ} \mathrm{C}$ by 2030 would amount to $78 \%$ (24-96\%). Generally, northern high latitude countries experience the largest changes in median warming and tropical Africa the largest changes in extremes. Our results emphasize the relevance of individual emitters, and in particular the top five emitters, in driving regional climate change across different time periods. 
Beusch, L., Gudmundsson, L., and Seneviratne, S. I. (ESD, 2020):

https://doi.org/10.5194/esd-11-139-2020

Meinshausen, M., Meinshausen, N., Hare, W. et al. (Nature, 2009): https://doi.org/10.1038/nature08017 